\title{
Combustion characteristics of cellulosic loose fibres
}

\author{
Özgür Ceylan ${ }^{1,2}$, Jenny Alongi ${ }^{3}$, Lieve Van Landuyt ${ }^{1}$, Alberto Frache $^{3}$ and \\ Karen De Clerck ${ }^{1, *}, \dagger$ \\ ${ }^{1}$ Department of Textiles, Ghent University, Ghent, Belgium \\ ${ }^{2}$ Department of Fashion Design, Anadolu University, Eskisehir, Turkey \\ ${ }^{3}$ Dipartimento di Scienza Applicata e Tecnologia, Politecnico di Torino, Alessandria, Italy
}

\begin{abstract}
SUMMARY
The aim of this paper is to study the combustion characteristics of loose fibrous cellulosic compounds through cone calorimeter measurements. The challenge in studying loose fibrous materials by cone calorimeter in a reproducible manner is met by optimizing various process parameters such as sample weight, heat flux and grid type. The method is validated using cotton fibres and fabrics with a range of flame retardant properties. Good correlations are obtained between the flame retardant content of samples and the heat release parameters for both the fibres and the fabrics. In addition, fibres from specific cotton cultivars showed statistically significant differences in heat release characteristics. This shows that valuable data concerning the combustion behaviour and the corresponding kinetics of loose fibrous compounds can be successfully gathered using a cone calorimeter. Thus, such data can be exploited to well define future fibre breeding programmes or fibre modification research. Copyright $@ 2012$ John Wiley \& Sons, Ltd.
\end{abstract}

Received 6 December 2011; Revised 3 April 2012; Accepted 12 June 2012

KEY WORDS: cellulosic fibres; cotton; cone calorimeter; heat release; combustion

\section{INTRODUCTION}

Cotton is the most important natural fibre used in the textile industry. It is a biodegradable and eco-friendly fibre with excellent moisture absorbency and light weight properties. A superior combination of comfort and aesthetics can be attained by the use of cotton fibres. The flammability of cotton products, however, is one of the problems posed to the textile industry. Government regulations and voluntary standards dictate the increasing use of flame retardant (FR) textiles mainly in work clothing, firefighter apparel, transportation, institutional carpets, bedding and military garments [1]. In order to comply with these regulations, cotton fibres are usually blended with synthetic fibres. Also, there are currently several types of chemical finishes that can be applied to cotton materials to impart FR properties. Particularly, halogenated-based and formaldehyde-based phosphorus FRs are suitable for cotton fibres. However, toxicological and environmental consequences of using such chemicals create a barrier to the development and applications of these finishes. Despite a significant consumer demand for pure cotton products, there is no commercial FR treatment available that alleviates these concerns and allows keeping the aesthetics of the garment. Thus, there is a need to develop new eco-friendly and durable means of producing FR cotton garments. To achieve FR properties in a more environmentally friendly manner, one may explore certain cotton cultivars with claimed intrinsic flame resistant properties [2] or use biotechnology to design new fibres with valuable characteristics [3]. Also, synthesis of aliphatic polyester (polyhydroxybutyrate) within cotton fibres has resulted in measurable improvements in thermal properties of bioengineered cotton fibres [4,5].

*Correspondence to: Karen De Clerck, Department of Textiles, Ghent University, Ghent, Belgium.

†E-mail: karen.declerck@ugent.be 
When developing and optimizing these new FR textile fibres, evaluating and analyzing their performance improvement is the most critical part. The capability of a testing method to differentiate small differences in flame retardancy among samples is of utmost importance for the success of the research and development work [6]. However, testing of FR materials presents specific technical and scientific challenges. These tests are commonly applied on finished fabrics rather than on loose fibres; yet, for fibre development research, there is a lack of resources to produce for all research lines the large amounts of fibres that are required for fabric production. A potential solution to this problem is to use small-scale flammability testing techniques to screen novel FR formulations prior to scale up for a larger size production.

The desire for quantitative analytical laboratory tests that can rank the fibrous compounds for their combustion behaviour has been the motivation to use cone calorimeter in the screening phase of novel FR formulations. The cone calorimeter utilizes the oxygen consumption principle and is suitable for relatively small-scale measurements [7-9]. However, the cone calorimeter set-up was originally designed to assess flammability properties of thick materials such as composites. A major challenge is to obtain reproducible cone calorimetric data for the extreme low density and fast burning fibrous specimens. Previous works have shown that when sample masses are below $5 \mathrm{~g}$, errors in cone calorimeter results are around $10 \%$ and care needs to be taken when comparing with other fire tests [10-12]. The test parameters of the cone calorimetric method have been adapted for textile fabrics that are already regarded as thermally thin samples $[11,13,14]$ but, up to our knowledge, have never been optimized for the much thinner cotton fibre samples.

This paper reports an initial investigation into the use of cone calorimeter as a screening tool for measuring the heat release parameters of fibrous cotton samples. Despite inherent limitations of the technique, we have attempted to evaluate its utility for testing the FR properties of extremely small quantities of fibre. The major challenges in obtaining accurate, precise and reproducible cone calorimetric data of thermally thin and extremely low weight loose fibre specimens have been achieved by modifying different testing parameters such as sample weight, heat flux and grid type. The method was evaluated using cotton fibres and fabrics with different FR properties. Also, different cotton lines were screened for differences in fibre combustion behaviour.

\section{EXPERIMENTAL}

\subsection{Materials}

Raw and scoured-bleached cotton fibres (Micronaire: 4.0-4.5, length: $28-29 \mathrm{~mm}$, strength: $28-30 \mathrm{cN} / \mathrm{tex}$ ) and cotton fabrics $\left(210 \mathrm{~g} / \mathrm{m}^{2}\right)$ from Utexbel (Ronse, Belgium) were used in this study. The fibres from the different cotton lines were obtained from Bayer CropScience N.V. (Ghent, Belgium). The fibres were opened, cleaned and deposited in the form of a loose web by using an Uster MDTA 3 laboratory blender. Fibres were passed through the machine at least three times to obtain homogenous mixtures.

\subsection{Preparation of flame retarded cotton fibres and fabrics}

Scoured and bleached cotton fibres and fabrics were treated with a solution of Aflammit ${ }^{\circledR} \mathrm{KWB}$ from Thor (Speyer, Germany) between 0 and $300 \mathrm{~g} / \mathrm{L}$ in the presence of $\mathrm{H}_{3} \mathrm{PO}_{4}(20 \mathrm{~g} / \mathrm{L})$. Samples were padded through a Gate $\mathrm{AG}$ Vaduz laboratory padder to control the pickup rates, dried at $60^{\circ} \mathrm{C}$ for $10 \mathrm{~min}$ and post-cured at $150^{\circ} \mathrm{C}$ for $5 \mathrm{~min}$. After curing, all samples were washed with warm and cold water. The $\%$ dry pick up of fibres and fabrics is shown in Table I.

\subsection{Preparation of the samples for the combustion tests}

According to normative ISO5660-1 [15] standard typically applied for the study of combustion behaviour in plastic specimens (thickness of $6 \mathrm{~mm}$ ), $100 \times 100 \mathrm{~mm}$ fibre samples were cut from the loose fibrous web and placed over the middle of an aluminium foil of $102 \times 102 \mathrm{~mm}$ with the shiny side towards the specimen and the corners folded (aluminium boot or tray). Further, the fibres were retained to this aluminium foil by different steel grid types in order to prevent suctioning of the sample by the exhaust 
Table I. Dry pick up of flame retarded cotton fibres and fabrics.

\begin{tabular}{lcc}
\hline Sample & Aflammit solution $(\mathrm{g} / \mathrm{L})$ & Dry pick up $(\%)$ \\
\hline Fibre & 0 & 0.48 \\
& 50 & 1.43 \\
& 100 & 3.62 \\
& 150 & 5.52 \\
Fabric & 200 & 7.71 \\
& 250 & 8.57 \\
& 300 & 10.95 \\
& 0 & 0.58 \\
& 50 & 2.31 \\
& 100 & 4.23 \\
\end{tabular}

hood. Finally, the prepared samples were placed over a ceramic backing pad for the measurements. Figure 1 illustrates the three grid types, and Table II summarizes their characteristics.

Before the measurements, all samples were conditioned for $24 \mathrm{~h}$ in a climate chamber at $23{ }^{\circ} \mathrm{C}$ and a relative humidity of $50 \%$. For a specific set of samples, different conditions of humidity have been taken in consideration, namely $25 \%, 35 \%, 50 \%$ and $75 \%$.

\subsection{Cone calorimeter}

A Fire Testing Technology Limited model FFT cone calorimeter was used, following the ISO 5660-1 standard. The fibres were burned for all experiments with a horizontal orientation, in air atmosphere and at three different predetermined external irradiances (heat fluxes) of 25,35 and $50 \mathrm{~kW} / \mathrm{m}^{2}$. The heat release rate measurements were taken every $2 \mathrm{~s}$. The instrument allows for the determination of total heat release (THR), the heat release rate (HRR) and the corresponding peak (pK HRR). For each sample type, the experiments were repeated at least three times to ensure the reproducibility of the measurements.

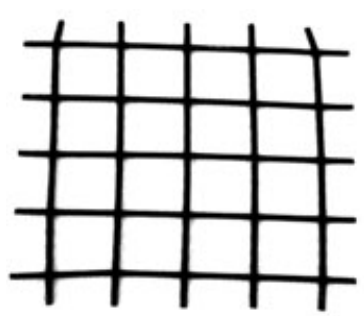

TYPE1

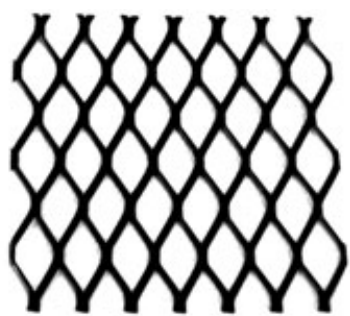

TYPE2

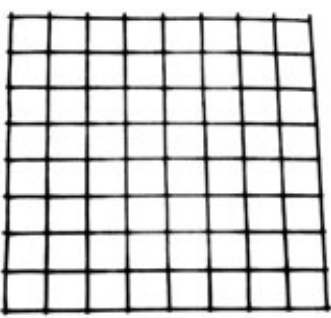

TYPE3

Figure 1. Three grid types employed in the present study.

Table II. Characteristics of grid types.

\begin{tabular}{lcccc}
\hline Grid & Weight $(\mathrm{g})$ & Thickness $(\mathrm{mm})$ & Mesh type & Size $(\mathrm{mm})$ \\
\hline TYPE1 & 25 & 2 & Square & 18 \\
TYPE2 & 28 & 2 & Lozenge & $11 / 23^{*}$ \\
TYPE3 & 12 & 1 & Square & 12 \\
\hline
\end{tabular}

\footnotetext{
*Diagonal size.
} 


\subsection{Statistical analysis}

Supplementary statistical analysis was performed on the obtained THR and pK HRR values by using oneway ANOVA with post Tukey test. A $95 \%$ confidence level was used for all tests of significance.

\section{RESULTS AND DISCUSSION}

With the advent of the cone calorimeter, several international standards have been established for polymer materials. Also, two ASTM standards have been developed in the field of textiles for wall covering composites, upholstered furniture and mattress components [16,17]. Nevertheless, it is not possible to follow the existing standards for loose fibrous samples because of the differences in the physical structure of the specimen. Therefore, a feasibility study needs to be performed on the key test parameters such as the sample weight, the relative humidity, the heat flux and the grid type. The protocol of the ISO 5660 is taken as a starting point, with it being a generally applied standard to polymeric materials (thickness of $6 \mathrm{~mm}$ ) and to textile fabrics.

\subsection{Influence of sample weight and heat flux}

The sample density can play an important role on the cone calorimeter test results. For textile fabrics, the thickness of the sample remains within the limits of the instrument even if multiple layers are needed to obtain a sufficient sample weight. In contrast, cotton fibres have a much lower density, thus requiring thicker samples to obtain a certain sample weight, with the actual thickness depending on the fibre packing density. To establish the optimal sample weight, 1, 2 and $3 \mathrm{~g}$ of fibre (with a fixed thickness of 8,12 and $18 \mathrm{~mm}$, respectively, to control the density of the specimen) were tested at different heat fluxes $\left(25,35\right.$ and $\left.50 \mathrm{~kW} / \mathrm{m}^{2}\right)$.

A heat flux of $25 \mathrm{~kW} / \mathrm{m}^{2}$ to irradiate the loose cotton fibre specimens results mainly in smouldering combustion for all weights tested (Figure 2). The intensity of the irradiating source and the density of fibres are not enough to provoke the flaming combustion of the cotton fibres, and this condition seems to be not affected by the sample weight.

Even at a heat flux of $35 \mathrm{~kW} / \mathrm{m}^{2}$ (Figure 3), a standard heat flux used within the established commercial aircraft regulations for some textiles [18], smouldering combustion rather than a flaming combustion is observed for several of the samples. This lack of flaming combustion for a number of samples did affect the reproducibility of the analysis for all sample weights.

At $50 \mathrm{~kW} / \mathrm{m}^{2}$ (Figure 4), a heat flux that represents severe fire exposure and consistent with the actual train fire tests [19], all samples showed flaming combustion. Within the range of samples tested, the 2-g sample showed the highest reproducibility. For the 1-g sample, the curves are too steep because of the low amount and the low density of material, resulting in fast burning of the sample. Especially the variation on the pK HRR was higher than for the 2- and 3-g samples. On the other hand, the HRR curves for the replicates of the 3-g samples are not well overlapping. These variations may be attributed to the presence of a substantial volume of air between the fibres, acting as an insulator affecting the

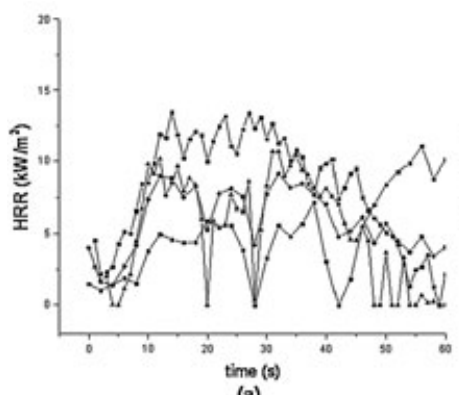

(a)

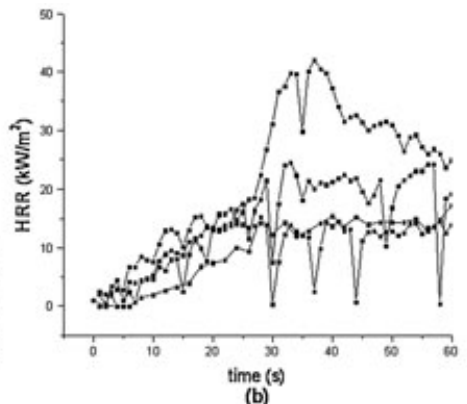

(b)

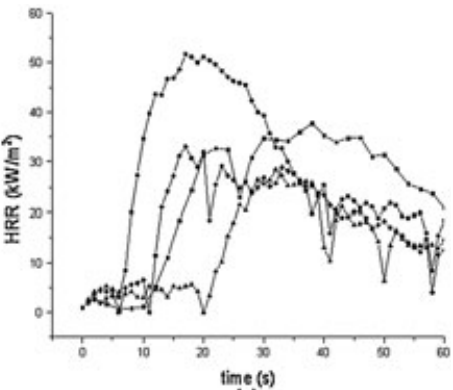

(c)

Figure 2. Heat release rate (HRR) curves of (a) 1, (b) 2 and (c) $3 \mathrm{~g}$ of cotton fibres obtained with a heat flux of $25 \mathrm{~kW} / \mathrm{m}^{2}$. 


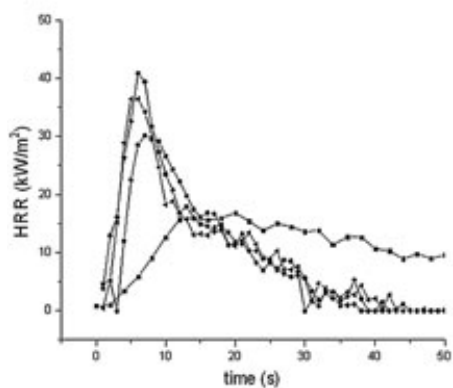

(a)

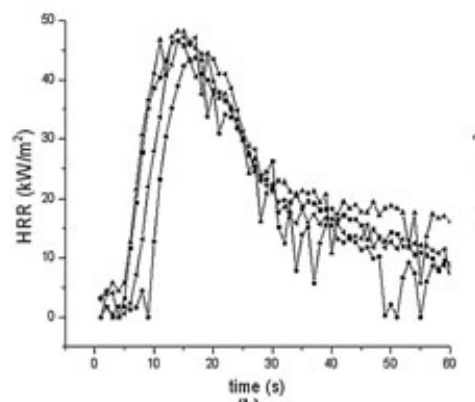

(b)

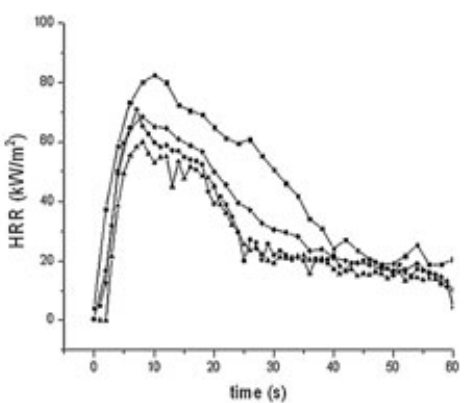

(c)

Figure 3. Heat release rate (HRR) curves of (a) 1, (b) 2 and (c) $3 \mathrm{~g}$ of cotton fibres obtained with $35 \mathrm{~kW} / \mathrm{m}^{2}$ of heat flux.

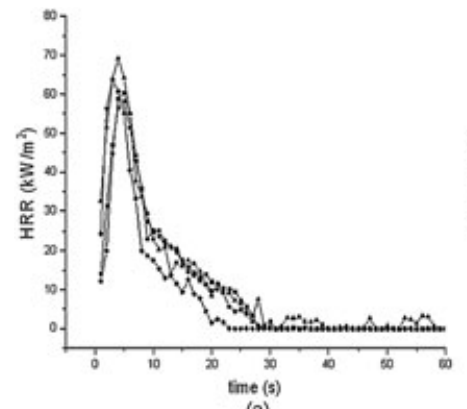

(a)

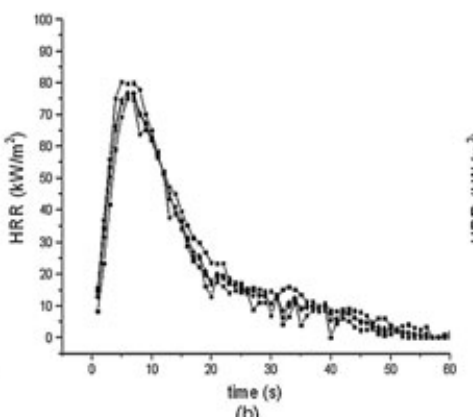

(b)

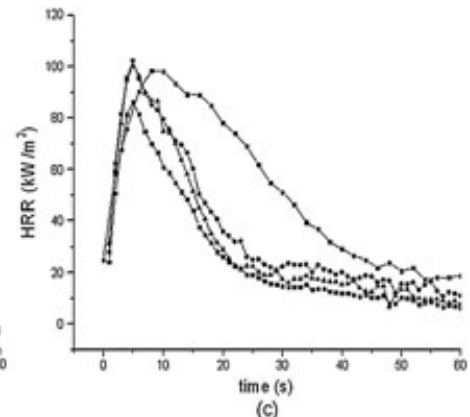

(c)

Figure 4. Heat release rate (HRR) curves of (a) 1, (b) 2 and (c) $3 \mathrm{~g}$ of cotton fibres obtained with $50 \mathrm{~kW} / \mathrm{m}^{2}$ of heat flux.

combustion behaviour, with this effect being more pronounced for the higher masses or thus thicker samples.

Thus, the optimal condition to test the combustion behaviour of loose cotton fibres is set at $2 \mathrm{~g}$ of fibrous material and a heat flux of $50 \mathrm{~kW} / \mathrm{m}^{2}$.

\subsection{Influence of the grid type}

Textile materials exposed to a heat flux tend to melt, curl or char that results in a change in specimen configuration [11]. The discrepancy in specimen configuration makes it difficult to obtain reproducible data because of changes in thickness and flux intensity imposed on the surface. Therefore, especially thin samples are tested using a metal grid to keep the initial distance between specimen and cone calorimeter heater constant and to reduce the deformation of the specimen. It is also known that employing such a grid has an effect on the time to ignition and pK HRR values [20]. In the case of fibrous samples, it is very crucial to fix the sample thickness and to stabilize the sample packing density by minimizing the free volume of the sample to improve the reproducibility. Analysis of cotton fibres in the absence of a grid did result not only in a non-reproducible specimen-heater distance but also in a too rapid combustion (data not shown). The specimen starts to burn immediately, and thus, the registered HRR curve results cut off.

For this reason, three different metal grid designs (Figure 1) were employed with $2 \mathrm{~g}$ of fibre at a heat flux of $50 \mathrm{~kW} / \mathrm{m}^{2}$. The grid types chosen are different in terms of weight, thickness and mesh type, as described in Table II. The TYPE1 grid is the reference, as pointed out by the ISO5660 standard. The TYPE2 grid has a different mesh type but similar weight and thickness compared with the TYPE1 grid, whereas the TYPE3 grid has a similar mesh type but a lower weight and thickness compared with the TYPE1 grid.

Figure 5 illustrates the effect of the grid type on the HRR for a heat flux of $50 \mathrm{~kW} / \mathrm{m}^{2}$. Obviously, the grid type has a significant effect on the combustion behaviour of the samples. Using the TYPE2 grid results mainly in smouldering combustion for a substantial number of replicates. TYPE1 and TYPE3 


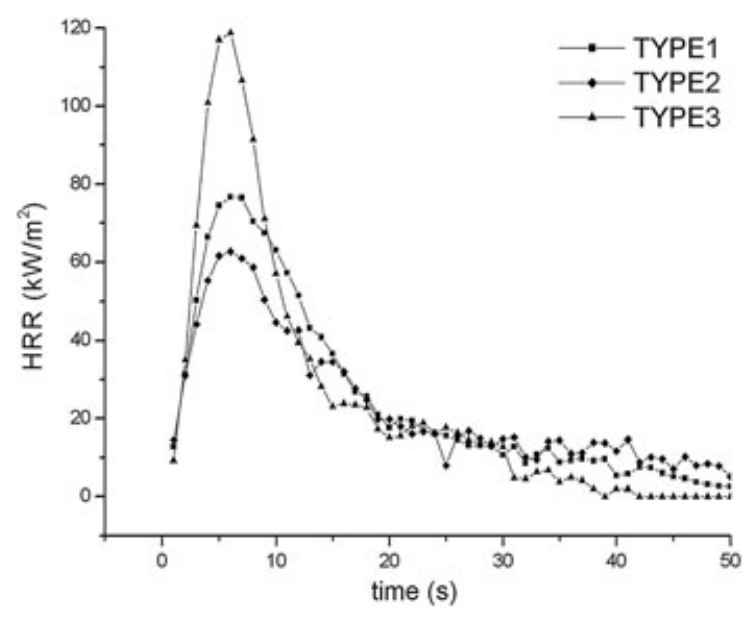

Figure 5. Heat release rate (HRR) curves of cotton fibres tested with different grids under $50 \mathrm{~kW} / \mathrm{m}^{2}$.

grids, however, did favour mostly flaming combustion. The reproducibility study on the replicates (Table III) showed the TYPE3 grid to be more reproducible than the TYPE1 grid. Also, probably the low heat absorption of TYPE3 minimizes the influence of the grid on results. Therefore, the TYPE3 grid with a heat flux of $50 \mathrm{~kW} / \mathrm{m}^{2}$ was used for all further fibre tests.

\subsection{Influence of the relative humidity}

Cotton fibres are highly hydrophilic; thus, a possible effect of the room humidity conditions during storage of the samples prior to testing may need to be taken into account. A set of samples conditioned at various relative humidity levels were tested under the optimised experimental conditions (sample mass of $2 \mathrm{~g}$, grid TYPE3, $50 \mathrm{~kW} / \mathrm{m}^{2}$ ). This resulted in only small differences for the parameters (THR and pK HRR) selected to perform the fibre screening with changes in relative humidity (Figure 6). Thus, the further testing of loose fibrous specimens have been performed after conditioning the samples at 50\% relative humidity, in agreement with the ISO5660 guidelines.

\subsection{Comparative study of the cone calorimetric procedure on flame retarded fibres and fabrics}

In literature, cone calorimetric testing was successfully used to determine the heat release parameters of fabrics [21-23]. In analogy to this, the suitability of the cone calorimeter to study the differences in the combustion behaviour of loose fibrous materials is further demonstrated on cotton fibres and fabrics with different FR characteristics. To produce FR fibres and fabrics, bleached cotton fibres and fabrics were treated with various concentrations $(0-300 \mathrm{~g} / \mathrm{L})$ of an FR agent. All other processing conditions including resin concentration, drying and curing temperatures were kept constant. Similar FR concentrations were comparable between fibres and fabrics (Table I). An increased concentration of FR agent will increase the availability of phosphorous groups and thus alter the combustion behaviour of the samples with a possible levelling off at higher concentrations.

Table III. Reproducibility results with three different grid types.

\begin{tabular}{|c|c|c|c|c|c|c|c|c|c|c|}
\hline \multirow[b]{2}{*}{ Heat flux } & \multirow[b]{2}{*}{ Grid type } & \multicolumn{3}{|c|}{ TTI (s) } & \multicolumn{3}{|c|}{ pK HRR $\left(\mathrm{kW} / \mathrm{m}^{2}\right)$} & \multicolumn{3}{|c|}{ THR $\left(\mathrm{MJ} / \mathrm{m}^{2}\right)$} \\
\hline & & Average & SD & $\mathrm{CV} \%$ & Average & SD & $\mathrm{CV} \%$ & Average & SD & $\mathrm{CV} \%$ \\
\hline \multirow[t]{3}{*}{$50 \mathrm{~kW} / \mathrm{m}^{2}$} & TYPE1 & 1.5 & 0.6 & 38.5 & 77.0 & 2.4 & 3.1 & 2.2 & 0.1 & 6.4 \\
\hline & TYPE2 & 2.5 & 0.7 & 28.3 & 41.7 & 24.4 & 58.6 & 1.5 & 0.7 & 45.1 \\
\hline & TYPE3 & 3.0 & 0.8 & 27.2 & 123.1 & 5.2 & 4.2 & 2.5 & 0.1 & 3.9 \\
\hline
\end{tabular}

Values reported are average of four replicates. pK HRR, peak heat release rate; THR, total heat release; TTI, time to ignition. 

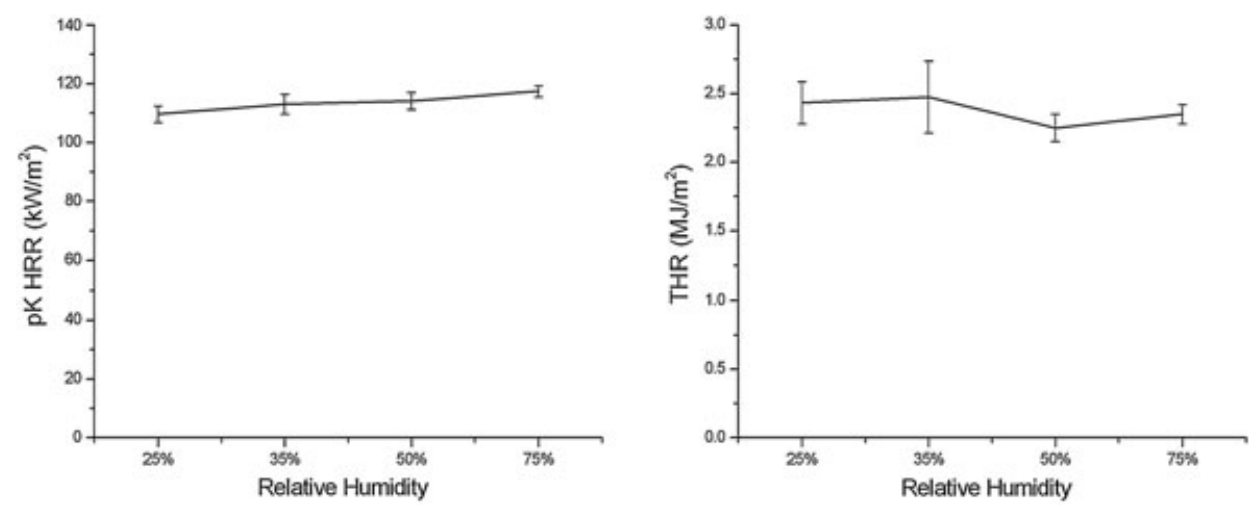

Figure 6. Peak heat release rate (pK HRR), total heat release (THR) and associated standard deviations of cotton fibres conditioned at different relative humidity conditions burned with TYPE3 grid under $50 \mathrm{~kW} / \mathrm{m}^{2}$.

Figure 7 illustrates that an increased FR amount results in a decrease in THR and pK HRR values, with the THR decrease levelling off at the higher FR concentrations. This is similar for both the fibres and the fabrics and is in agreement of what may be expected for pK HRR values from literature [14,24] on FR treated fabrics. At all FR concentrations, fabrics showed higher THR and pK HRR values than the fibres. This might be attributed to the differences in density of the specimens. Apart from the THR values for the higher concentration of FR agent (200, 250 and $300 \mathrm{~g} / \mathrm{L}$ ) on the fibres, all results showed an acceptable reproducibility with CV $<13 \%$ [11]. The similar trend for both the fibres and the fabrics shows the suitability of cone calorimetry to test loose fibrous samples. Also, the calculated relationship between the pK HRR values and the dry pick up of FR on fibres and fabrics is fairly linear $\left(R^{2}>0.91\right.$ for fibres and $R^{2}>0.97$ for fabrics), which further demonstrates the reliability of the proposed method to determine the differences in combustion behaviour of loose fibres.

\subsection{Screening of fibres from different cotton lines}

The end use of the screening tests is to reliably detect differences in combustion behaviour of extremely small amounts of fibrous compounds. In literature, derived cone calorimetric parameters such as critical heat flux, pK HRR at zero incident heat flux and fire growth index were used to rank fabrics for their potential burning hazard [11]. However, because of the short ignition times and the limited availability of the samples, the comparisons are restricted to the THR and pK HRR parameters. The THR and pK HRR are believed to be crucial determinants of combustion behaviour for materials [25]. Such parameters can influence the rate of burning and the rate of mass loss, and determine whether the surrounding material will ignite. The pK HRR can indicate the severity with which a material burns at
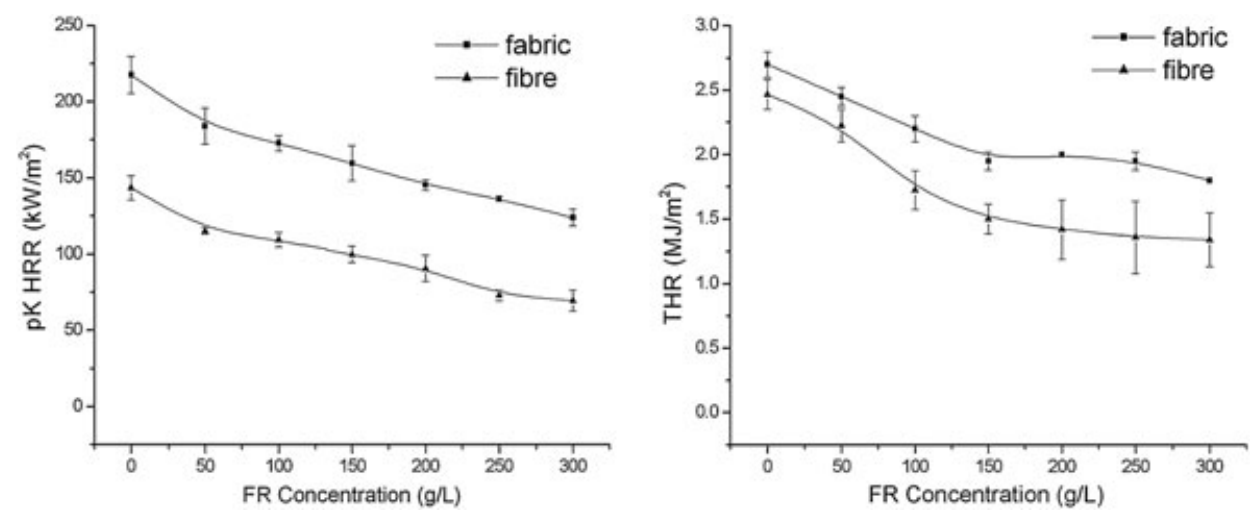

Figure 7. Peak heat release rate (pK HRR), total heat release (THR) and associated standard deviations of flame retardant (FR) cotton fabrics and fibres treated with various concentration of an FR agent. 
its highest rate of combustion and is used to calculate the fire growth index [11,26]. Thus, measurement of these heat release parameters can provide an important first indication needed for the research in fibre development process. To further demonstrate the capability of the method to detect the differences in combustion behaviour of small amounts of fibrous compounds, it was used to test fibres from different cotton cultivars. The combustion behaviours of these lines in terms of THR and pK HRR have been compared and plotted, together with their standard deviations, in Figure 8. One-way ANOVA analysis was performed followed by a Tukey test as post hoc on THR and pK HRR values to determine whether the obtained differences between different lines are consistent and statistically significant ( $F$ : Fisher value, $p$ : probability).

The ANOVA result indicated significant differences in THR and $\mathrm{pK}$ HRR values among the cotton lines $\left(F_{\mathrm{HRR}}=27.270, F_{\mathrm{pK}}\right.$ HRR $\left.=49.861, p<0.05\right)$. According to the Tukey test, the THR values for lines 1,2 and 3 are statistically lower than those values for lines 8,9 and 10. The differences in THR values among other lines are statistically insignificant. Similarly, the pK HRR values for lines 1 and 2 are statistically lower, and for lines 9 and 10, the pK HRR values are significantly higher than the other lines. The differences in pK HRR values among lines 5, 6, 7 and 8 are statistically insignificant. However, the pK HRR values of the latter group are statistically higher than those of lines 3 and 4 . Obviously, there are differences in combustion behaviour of cotton fibres from different varieties, and the optimised methodology can be used to detect these differences.

\section{CONCLUSIONS}

In the present work, attempts have been made to determine heat release parameters of extremely small amount of loose cotton fibres by using cone calorimeter, as to aid the fibre development research where only very limited quantities of fibre are available. The major challenge in obtaining reproducible and reliable cone calorimetric data of these low density and thermally thin materials was overcome by varying different testing parameters such as sample weight, heat flux and grid type. The suitability of the method to study combustion behaviour of loose fibres has been further demonstrated using cotton fibres and fabrics treated with different concentrations of FR. A similar trend was observed for fibres and fabrics that gives an important indication for the feasibility of the method to test loose fibrous samples, even within the present limitations of the cone calorimeter technology.

The method was also used to test a series of cotton fibre cultivars, and statistically significant differences were observed in terms of THR and pK HRR values. Despite inherent limitations of the cone calorimetric method in testing small size specimen, overall, it can still be used as a screening tool to provide valuable indications on the differences in combustion behaviour for loose fibres in fibre development research.
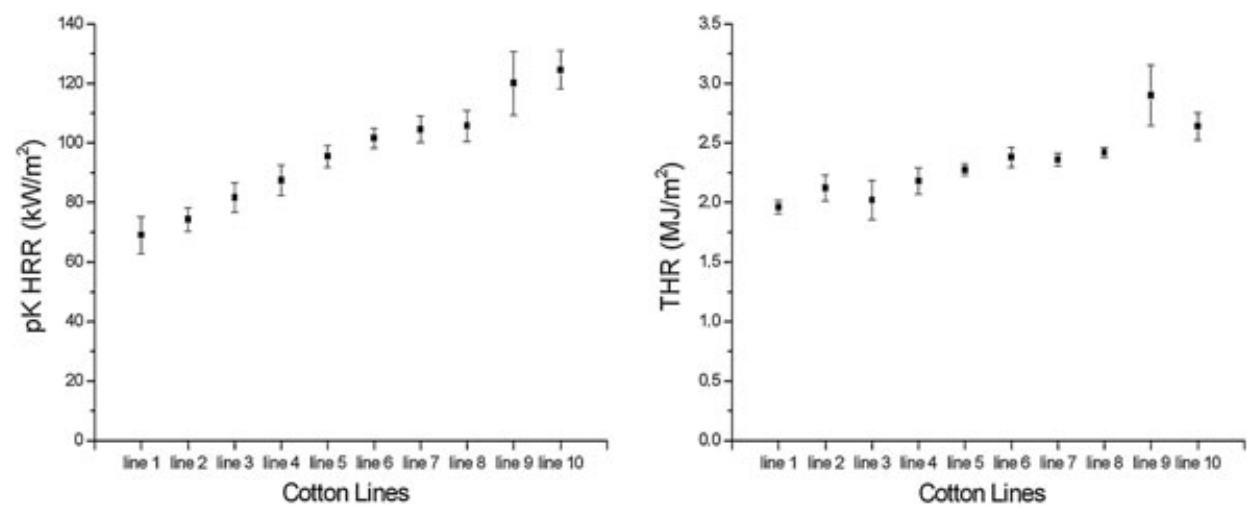

Figure 8. Peak heat release rate (pK HRR), total heat release (THR) and associated standard deviations of different cotton lines. 


\section{ACKNOWLEDGEMENTS}

This work was supported by the Institute for the Promotion of Innovation by Science and Technology in Flanders (IWT) (project number IWT090505). The authors also would like to thank the European Commission for the economical funding of FRONT (Flame Retardant On Textiles) project 2008/2010 (7th Framework Program, contract no. 222486), Fabio Cuttica for the technical support and Professor Giovanni Camino for the fruitful discussions.

\section{REFERENCES}

1. Weil ED, Levchik SV. Flame retardants in commercial use or development for textiles. Journal of Fire Sciences 2008; 26:243-281.

2. Fox SV. Naturally flame resistant cotton fiber. 1996; U.S. Patent 5496623.

3. Ceylan Ö. Innovative screening of novel bioengineered cotton fibers containing oligochitin. Textile Research Journal 2012; 82:801-809.

4. Poirier Y. Production of new polymeric compounds in plants. Current Opinion in Biotechnology 1999; 10:181-185.

5. John ME, Keller G. Metabolic pathway engineering in cotton: biosynthesis of polyhydroxybutyrate in fiber cells. Proceedings of the National Academy of Sciences of the United States of America 1996; 93:12768-12773.

6. Yang CQ, He Q, Lyon RE, Hu Y. Investigation of the flammability of different textile fabrics using micro-scale combustion calorimetry. Polymer Degradation and Stability 2010; 95:108-115.

7. Huggett C. Estimation of rate of heat release by means of oxygen consumption measurements. Fire and Materials 1980; 4:61-65.

8. Babrauskas V. Development of the cone calorimeter: a bench-scale heat release rate apparatus based on oxygen consumption. Fire and Materials 1984; 8:81-95.

9. Babrauskas V, Baroudi D, Myllymäki J, Kokkala M. The cone calorimeter used for predictions of the full-scale burning behaviour of upholstered furniture. Fire and Materials 1997; 21:95-105.

10. Horrocks AR, Kandola BK, Smart G, Zhang S, Hull TR. Polypropylene fibers containing dispersed clays having improved fire performance. I. Effect of nanoclays on processing parameters and fiber properties. Journal of Applied Polymer Science 2007; 106:1707-1717.

11. Nazaré S, Kandola B, Horrocks AR. Use of cone calorimetry to quantify the burning hazard of apparel fabrics. Fire and Materials 2002; 26:191-199.

12. Filipczak R, Crowley S, Lyon RE. Heat release rate measurements of thin samples in the OSU apparatus and the cone calorimeter. Fire safety journal 2005; 40:628-645.

13. Tata J, Alongi J, Carosio F, Frache A. Optimization of the procedure to burn textile fabrics by cone calorimeter: part I. Combustion behaviour of polyester. Fire and Materials 2011; 35:397-409.

14. Hshieh F-Y, Beeson HD. Flammability testing of pure and flame retardant-treated cotton fabrics. Fire and Materials $1995 ; 19: 233-239$.

15. ISO 5660-1:2002. Reaction-to-fire tests — heat release, smoke production and mass loss rate — part 1: heat release rate (cone calorimeter method). Geneva, Switzerland 2002.

16. ASTM E1740. 10 standard test method for determining the heat release rate and other fire-test-response characteristics of wall covering or ceiling covering composites using a cone calorimeter. ASTM, USA, 2010.

17. ASTM E1474. 10 standard test method for determining the heat release rate of upholstered furniture and mattress components or composites using a bench scale oxygen consumption calorimeter. ASTM, USA, 2010.

18. William F, Huges J. Federal Aviation Administration Regulation FAR (and JAR)1. 25.853 Part IV. Appendix, Technical Center-AARO-440, USA, 1986.

19. Peacock RD, Bukowski RW, Reneke PA, Averill JD, Markos SH. Development of a fire hazard assessment method to evaluate the fire safety of passenger trains. 7th International Conference and Exhibition. Proceedings, San Antonio, USA, 2001.

20. Mikkola E. Communication: raised grid for ignitability and RHR testing. Fire and Materials 1993; 17:47-48.

21. Bourbigot S, Flambard X, Poutch F, Duquesne S Cone calorimeter study of high performance fibres—application to polybenzazole and p-aramid fibres. Polymer Degradation and Stability 2001; 74:481-486.

22. Kotresh TM, Indushekar R, Subbulakshmi MS, Vijayalakshmi SN, Prasad ASK, Agrawal AK. Evaluation of commercial flame retardant polyester curtain fabrics in the cone calorimeter. Journal of Industrial Textiles 2006; 36:47-58.

23. Spearpoint M, Olenick SM, Torero JL, Steinhaus T. Ignition performance of new and used motor vehicle upholstery fabrics. Fire and Materials 2005; 29:265-282.

24. Lecoeur E, Vroman I, Bourbigot S, Delobel R. Optimization of monoguanidine dihydrogen phosphate and amino propylethoxysilane based flame retardant formulations for cotton. Polymer Degradation and Stability 2006; 91:1909-1914.

25. Price D, Liu Y, Hull TR, Milnes GJ, Kandola BK, Horrocks AR. Burning behaviour of foam/cotton fabric combinations in the cone calorimeter. Polymer Degradation and Stability 2002; 77:213-220.

26. Langille K, Nguyen D, Veinot DE. Inorganic intumescent coatings for improved fire protection of GRP. Fire Technology 1999; 35:99-110. 